\title{
Mechanical properties of fullerite and diamondlike carbon films using surface acoustic waves and nanoindentation
}

Richter, Asta, Ries, Ronald

Asta Richter, Ronald Ries, "Mechanical properties of fullerite and diamondlike carbon films using surface acoustic waves and nanoindentation," Proc. SPIE 3725, International Conference on Solid State Crystals '98: Epilayers and Heterostructures in Optoelectronics and Semiconductor Technology, (8 April 1999); doi: 10.1117/12.344714

Event: International Conference on Solid State Crystals '98, 1998, Zakopane, Poland 


\title{
Mechanical properties of fullerite and diamond-like carbon films using surface acoustic waves and nanoindentation
}

\author{
Asta Richter and Ronald Ries \\ Engineering Physics, University of Applied Sciences Berlin-Wildau, Bahnhofstrasse 1, \\ D-15745 Wildau, Germany
}

\begin{abstract}
$\mathrm{C}_{60}$ and amorphous diamond-like carbon (DLC) films have been grown by thermal evaporation and laser ablation techniques at different substrate temperatures and on various substrates. The elastic modulus and the hardness of the films have been investigated by surface acoustic waves and nanoindentation. Both methods are completely new and designed for investigations of very thin films. For homogeneous $\mathrm{C}_{60}$ films the Young's modulus was found to be $14 \mathrm{GPa}$ and the Poisson's ratio of 0.2 . The measured nanohardness of $167 \mathrm{MPa}$ corresponds with the microhardness value of $130 \mathrm{MPa}$. There is a correlation between deposition techniques and hardness as well as Young's modulus for DLC films.
\end{abstract}

Keywords: amorphous carbon films, $\mathrm{C}_{60}$ films, deposition techniques, scanning force microscopy, nanoindentation, surface acoustic waves, Young's modulus.

\section{INTRODUCTION}

Structural and mechanical properties of molecular soft $\mathrm{C}_{60}$ films are different from those of amorphous or crystalline carbon films. Both types of carbon films have potential applications in hard and/or optical coatings. These materials are also considered to be biocompatible with applications as coating materials in environmental techniques and on medical devices, implants, grafts or other biological systems.

Fullerene films ${ }^{1}$ contain $\mathrm{C}_{60}$ molecules, which form a solid fcc structure by van der Waals forces. They can be grown on different substrates. The growth mode is very different and depends on the mobility of single $\mathrm{C}_{60}$ molecules on the surface and their adherence to the substrate. Generally the growth mode is an island growth, however they can be also grown layer by layer on suitable substrates with a very low molecular surface roughness. These fullerene films are then epitaxial. $\mathrm{C}_{60}$ films can be grown to a few monolayers but also to thick films of a few $\mu \mathrm{m}$. They represent a soft material which can be used as interlayer in hard coatings or in combination with biomaterial.

The structure and morphology of different carbon films ${ }^{2}$ is responsible for their physical properties and depends on the deposition technique and several process parameters. Hard carbon coatings can include hydrogen. The investigated samples in this paper are free from hydrogen and characterised by a certain portion of $\mathrm{sp}^{2}$ and $\mathrm{sp}^{3}$ bonds. Hard diamond-like (DLC) carbon films contain a high amount of strong $\mathrm{sp}^{3}$ bonds and have a high hardness estimated wear treatment, scratch testing and density and Young's modulus measurements. Because of internal stress the films cannot be grown to a thickness of more than $500 \mathrm{~nm}$ without any additional treatment. Thus microhardness measurements are not straightforwardly applicable.

The classification of carbon films is not a simple procedure. Investigations with scanning force microscopy (SFM) characterise the surface morphology and grain size distribution including the roughness of the film surface. The same tip for scanning the surface to obtain an image can be used to make indents and scratches on the surface by application of forces in the range of $\mu$-Newtons and $m$-Newtons. That very recent method gives hardness values on nanoscale and can be applied to thin films. From the load-depth relation the elastic part can be separated which gives the Young's modulus of the film.

Email: richter@pt.tfh-wildau.de; phone: +49-3375-507217; fax: +49-3375-501 094 
These values are compared with Young's modulus measurements obtained by investigation of surface acoustic waves and are in good agreement. Thus material parameters are found to classify the variety of carbon films.

\section{EXPERIMENTAL DETAILS}

\subsection{Nanoindentation procedure}

In the macroscopic regime hardness is determined by the applied normal load divided by either the curved surface area or the projected area of contact between the indenter and the material being tested under load. Another possibility is to measure continuously the increasing load and the depth displacement as an indentation is made ${ }^{3}$. Two mechanical properties are measured most frequently using load depth sensing indentation techniques. These are the elastic modulus and the hardness. Data are obtained from a complete cycle of loading and unloading.

With the new scanning probe microscopy forces of a few p-Newtons up to a few $\mathrm{m}$-Newtons can be generated and measured depending on the cantilever force constant. With a nanoindenter device it is possible to scan the surface of a material with a tip, to register the interaction forces and thus to obtain a surface profile of the sample. The tip can be also used to apply a bigger load and to create an indent in the surface. The load-depth characteristics are measured during the indentation process on a scale of $\mu$-Newtons up to a few $m$-Newtons with indents in the range of nanometers. Despite the registration of the load-depth profile the indentation area can be in situ imaged by the same tip. Plastic and elastic portions of the indentation process can be distinguished. The hardness is calculated by $\mathrm{H}_{\mathrm{N}}=\mathrm{K} \mathrm{L}_{\max } / \mathrm{h}_{\mathrm{p}}{ }^{2}$ with the maximum load $\mathrm{L}_{\max }$, the plastic portion of the indentation depth $h_{p}$ and a constant resulting from the geometry and the device parameters which has been partly theoretically estimated but depends also on the calibration procedure. The Young's modulus E of the film can be calculated with

$$
\left(\mathrm{K} / \mathrm{h}_{\mathrm{p}}\right) \mathrm{dL} / \mathrm{dh}=\left(1-\mathrm{v}^{2}\right) / \mathrm{E}+\left(1-v_{\text {ind }}{ }^{2}\right) / \mathrm{E}_{\text {und }}
$$

$v$ is the Poisson's ratio of the film whereas $v_{\text {ind }}$ and $E_{\text {nnd }}$ are the Poisson's ratio and the Young's modulus of the tip.

All experiments are performed with the nanoindenter TriboScope with a diamond tip of a three-sided pyramid with $90^{\circ}$ angle as shown in the scanning electron microscopy picture of Fig. la. The corresponding geometry of the tip is presented in Fig. Ib giving the theoretical relations between the depth and the indentation area. The diamond tip is oriented to the 111 direction. The indentation area on the film surface is imaged using the same diamond tip. A typical example with a line scan is shown in Fig. 2a. With the line scan analysis the length of the indent as well as the height can be measured. The sensitively measured data of load and corresponding depth are registered in the diagram of Fig. $2 \mathrm{~b}$. The height values of the line scan obtained by SFM do not always agree with the depth data since the tip with its robust geometry cannot follow the surface profile in detail. Moreover, the applied forces are much higher than in the sensitive scanning mode with a tip of a low force constant. The relation between the size of the indentation area and the depth height are well reproduced with a $=2.43$ h. The values in Fig. 2 are measured on a $\mathrm{C}_{60}$ film on mica and represent typical images and values for the applied method. With a maximum load of $155 \mu \mathrm{N}$ an indentation depth of $45 \mathrm{~nm}$ is registered.

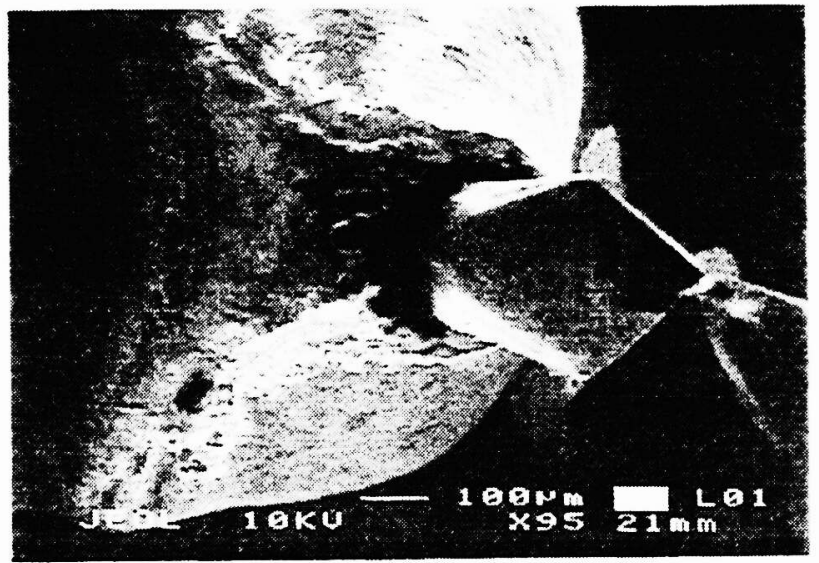

a

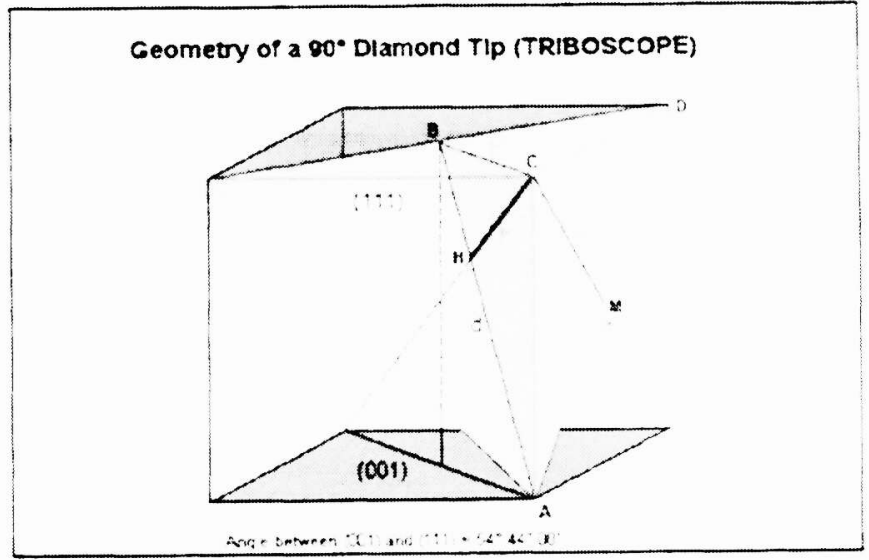

b

Fig. 1. Scanning electron microscopy image of the diamond tip (a) and corresponding crystal geometry (b) 
Nanometer scale patterning can be done successfully by scratching directly the sample surface with the tip. Different line widths and depths are possible depending on the tip geometry and the applied forces as well as on the film material. Hardness and elasticity of the coating material are sensitive properties to improve a nanolithography process within a triboscope. Because of drift processes the reproducibility of the obtained pattern is not always given.

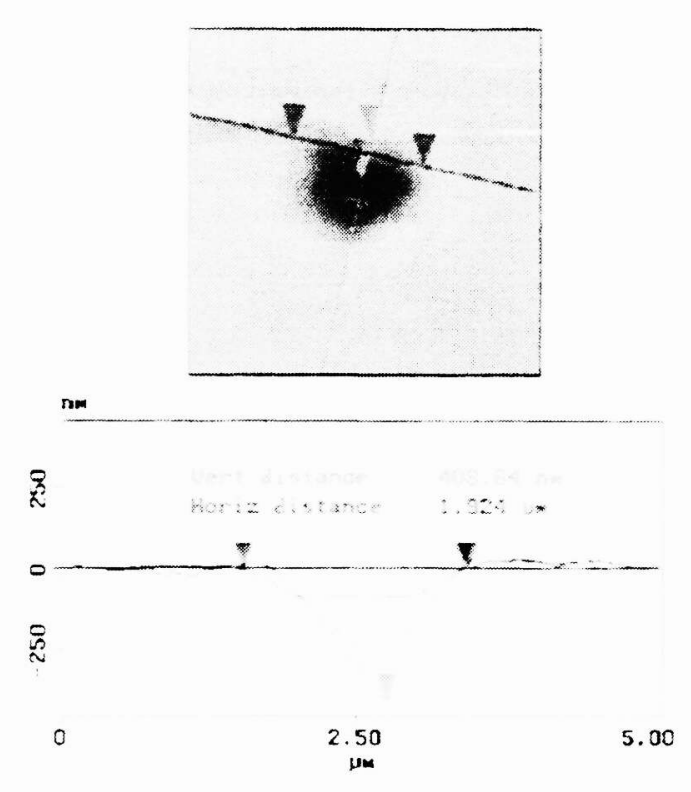

a

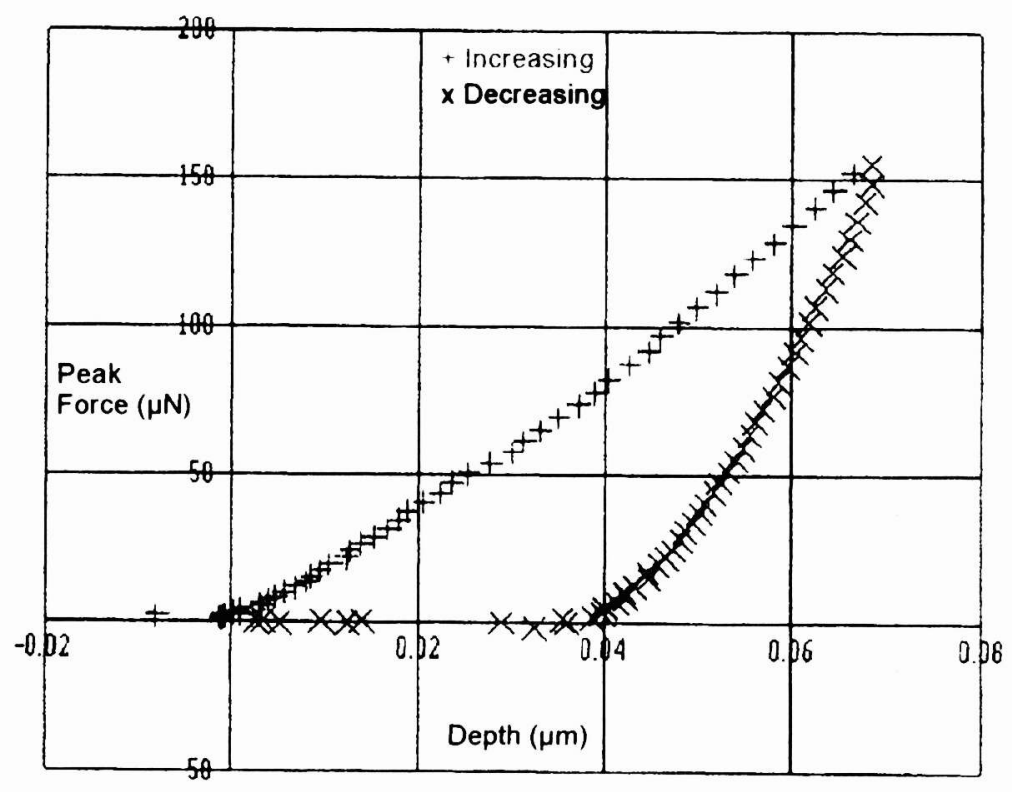

b

Fig. 2. Scanning force microscopy image of an indented area with cross section analysis (a) and corresponding loaddisplacement graph (b).

\subsection{Surface acoustic waves}

A suitable method to determine the Young's modulus is to study the propagation of the velocity of ultrasonic surface waves 4.5. Surface acoustic waves are an ideal tool to study the elastic properties of thin films on a substrate in a non-destructive way. The influence of the coating on the surface wave propagation depends on the ratio of the film thickness $d$ to the wavelength $\lambda$. Surface waves in a wide range of $d / \lambda$ are necessary to obtain accurate material parameters of the film. Therefore, frequencies of $100 \mathrm{MHz}$ and more must be used as surface waves to investigate very thin films. The technical problems related to generating and receiving such surface waves with a big bandwidth are overcome by application of laser induces surface waves. A pulsed nitrogen laser was used in the investigation process. For laser pulses smaller than 20 ns the bandwidth of the surface waves is limited by the dimension of the laser focus. Thus a focal line of the laser beam on the sample surface is projected which generated a surface wave with propagation perpendicular to the focal line. The surface wave pulses are analysed with a polymer transducer at different distances. The phase velocity of that surface wave as a function of frequency over a length of $5 \mathrm{~mm}$ minimum can now be determined. Thus a whole velocity spectrum including the dispersion curve is obtained. For a sample without a surface film the phase velocity would not depend on frequency. If the dispersion curve decreases a normal dispersion is described with the surface wave velocity of the film lower than that on the substrate. With a nearly linear curve shape the two parameters such as the elastic module of the film and the substrate can be calculated by the regression procedure. With known values of the substrate the Young's modulus can be obtained.

\section{RESULTS}

$\mathrm{C}_{60}$ films of different thickness and on various substrates such as glass, mica and silicon have been investigated by nanoindentation. Load-displacement graphs with different peak forces for a $\mathrm{C}_{60}$ film on mica and silicon are shown in Fig. 3. A certain peak force results in a maximum load with a corresponding depth profile. All shown load-displacement curves have a different shape and thus represent various features. It is known from microhardness measurements that the depth of the indented area should be only $10 \%$ of the film thickness to avoid the influence of the underlying substrate. For very thin films this rule becomes more important as shown in the series of Fig. 3. With a film thickness of $1 \mu \mathrm{m}$ for a fullerene film 

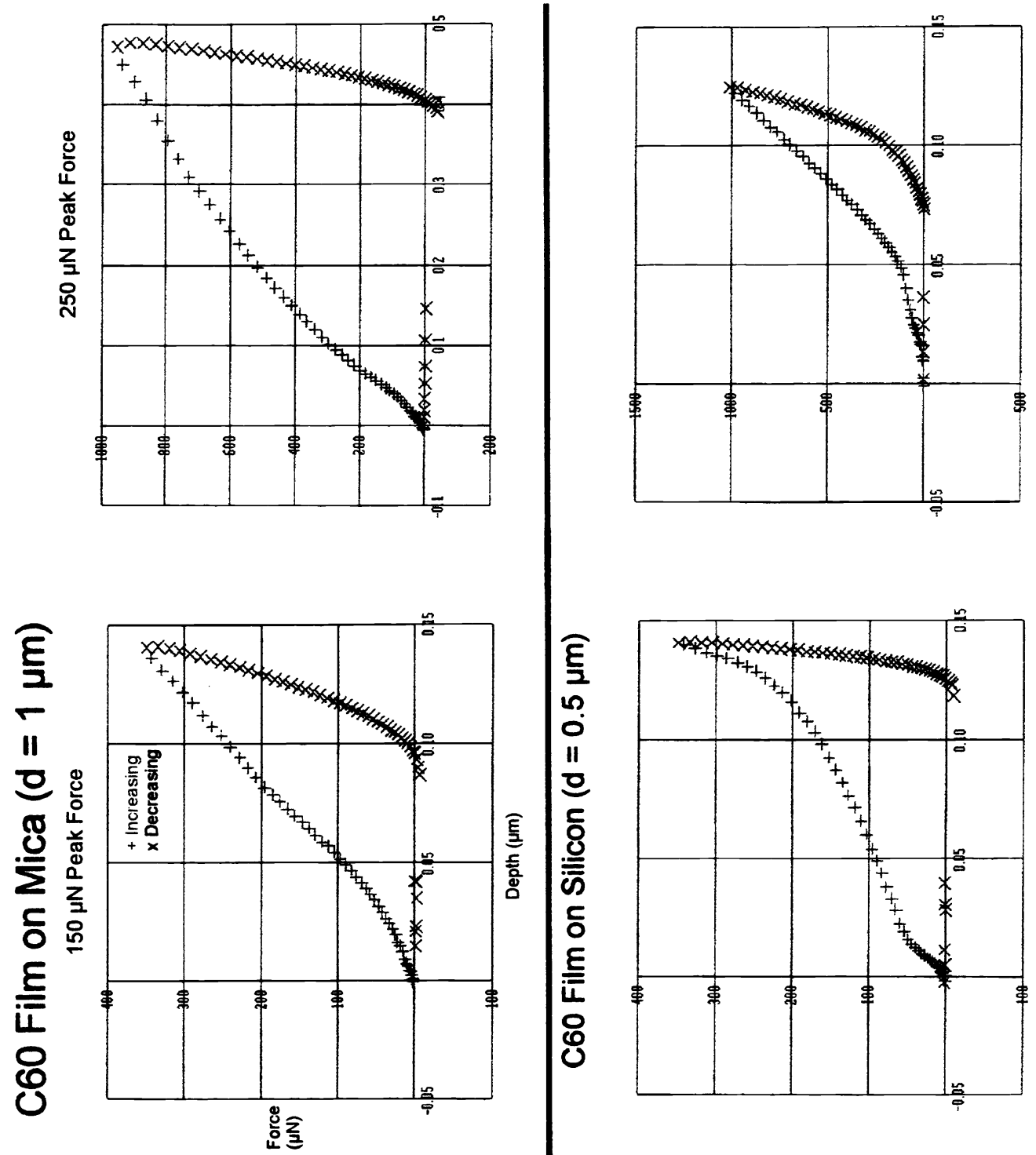

崩

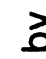

ลे

.

옹

동

음

즘

Z

동

은

(1)

등

ญ్
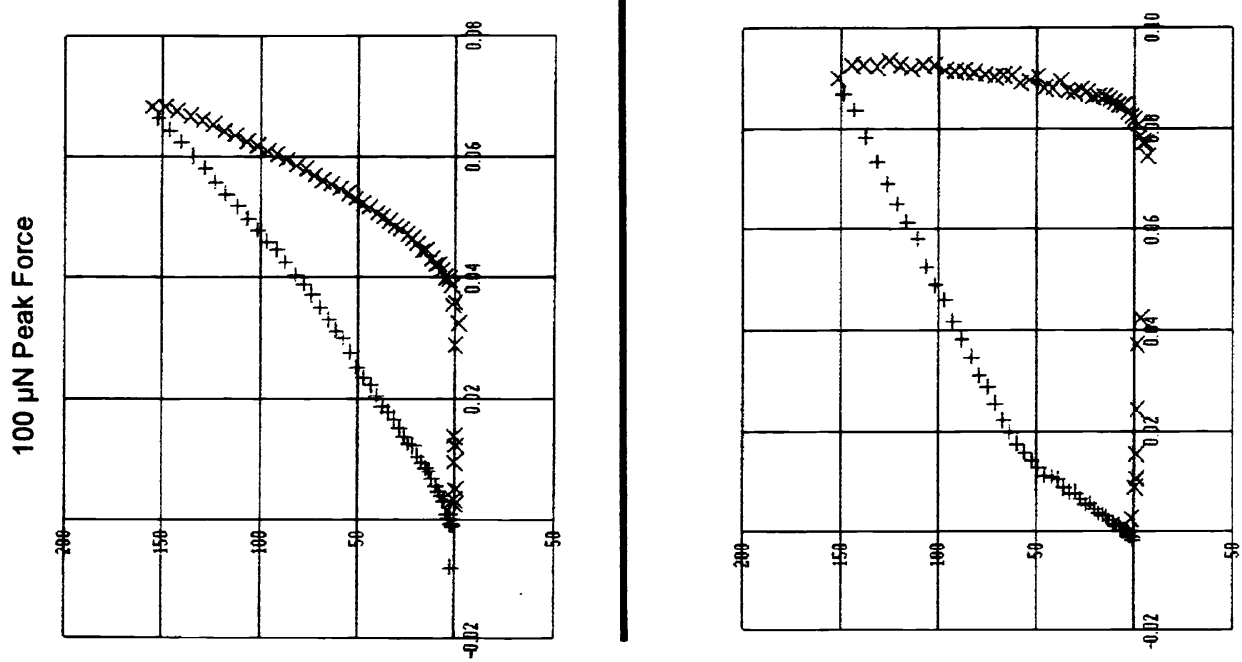

\begin{tabular}{l}
$\frac{0}{0}$ \\
$\frac{0}{0}$ \\
$\frac{0}{0}$ \\
0 \\
\hline 0 \\
0 \\
0 \\
0
\end{tabular}

in 
on mica the indentation depth should not exceed $100 \mathrm{~nm}$. An indentation depth of $420 \mathrm{~nm}$ is obtained with a peak force of $250 \mu \mathrm{N}$. This value does not give the correct hardness of the C60 film and contains features from the underlying substrate. The increasing load-depth curve changes its shape between 100 and $200 \mu \mathrm{N}$ load that can be seen in more detail on the graph obtained with $150 \mu \mathrm{N}$ peak force. Thus only very small applied forces give a reasonable nanohardness value which was estimated as an average from a series of indents with $167 \mathrm{MPa}$ for a $\mathrm{C}_{60}$ film. This nanohardness value is slightly higher than the measured microhardness value of $130 \mathrm{MPa}$ for a $5 \mu \mathrm{m}$ thick $\mathrm{C}_{60}$ film on mica. Increasing load in the microhardness measurements result again in the microhardness value of the mica substrate. We cannot explain at the moment why the nanohardness of $\mathrm{C}_{60}$ films is higher. It can either result from the morphology of the film which is much more important for nanohardness measurements or from the model features which are at the moment the same for the micro- and nanohardness procedure. More detailed investigations of the tip-surface interaction during the indentation process are necessary to explain the features. Computer simulation studies are under investigation to get a more complex view into the nanoindentation mechanism.

All shown graphs for nanoindentation into a $500 \mathrm{~nm}$ thick $\mathrm{C}_{60}$ film on silicon show the influence of the substrate. The loaddisplacement curve for $100 \mu \mathrm{N}$ peak force is comparable with that of a $\mathrm{C}_{60}$ film on mica with $250 \mu \mathrm{N}$ peak force. The tip passes gradually areas of different hardness. For a peak force of $250 \mu \mathrm{N}$ the coating does not play a role and the hardness value for silicon with $7.2 \mathrm{GPa}$ is reproduced. With a peak force of $150 \mu \mathrm{N}$ the transition between coating and substrate is well visible.

The obtained nanohardness value for $\mathrm{C}_{60}$ films on silicon and glass is slightly smaller compared with $\mathrm{C}_{60}$ films on mica. We attribute this fact to the different morphology of the fullerene films. The diamond tip of the nanoindenter feels the topography of the sample surface sensitively. $\mathrm{C}_{60}$ films on silicon and glass are grown in the island mode and contain hillock like grains of different size ${ }^{1}$. $\mathrm{C}_{60}$ films on mica grow layer by layer with large grains of epitaxial orientation up to $500 \mathrm{~nm}$ diameter in lateral size. We suspect that the tip comes across on areas between the grains and directly on grains for very small applied load values and is not able to integrate over the complete morphology. For the epitaxial $\mathrm{C}_{60}$ films on mica a homogeneous area is probably tested in contrast to a polycrystalline fullerene film structure on silicon and mica. It can be also assumed that the epitaxial films in general have more pronounced mechanical properties on nanoscale features because of their perfect and oriented structure. Here again further investigations are necessary.

The tip can be also used to produce scratches and to write definite nanostructures in the film material (Fig. 4). We applied the quasistatic mode where the probe tip is moved at certain load forces over the sample and thereby generating a mechanical surface modification. Reproducible line structures are written with $35 \mu \mathrm{N}$ load in a $\mathrm{C}_{60}$ film as shown in Fig. 4. The line depth varies between 7.8 and $15.1 \mathrm{~nm}$ and depends on the speed. Moreover, there is a drift noticed in the onset of the lines, which turns out to be also a problem in writing other figures with a computer aided procedure.

Beside hardness the elastic modulus of materials is another important feature to characterise the mechanical properties of a film. The load-displacement curve contains elastic parts beside the plastic deformation, which are used to calculate the nanohardness. The decreasing load-depth profile characterises elastic and plastic contributions. It is however not very simple at the present state of our preliminary investigations to separate the elastic part with a high accuracy. Thus we measured the Young's modulus of $\mathrm{C}_{60}$ films and also DLC films by ultrasonic sound waves on specially prepared samples with larger lateral dimensions. Silicon was used as substrate material because all properties of the material are very well known. Based on the substrate as reference material the frequency dispersion curve is obtained which shows a normal dispersion with a linear frequency dependence of the sound velocity in a certain area. In Fig. 5 the frequency dependence of sound propagation velocity for a $\mathrm{C}_{60}$ film on silicon is shown. The Young's modulus of the film can be calculated from the slope of the dispersion curve with the known value of the film density. With a density of the $\mathrm{C}_{60}$ film of $1.56 \mathrm{~g} / \mathrm{cm}^{3}$ the Young's modulus of $\mathrm{C}_{60}$ films was calculated with $14 \mathrm{GPa}$ and a Poisson's ratio of 0.2 . Similar results are published in the literature 5 .

The in big detail described procedure for nanohardness and Young's modulus investigations on $\mathrm{C}_{60}$ films has been also applied to DLC films. Contrary to fullerene films which can be also grown to a certain thickness DLC films are always very thin and reach a maximum thickness of $500 \mathrm{~nm}$ in dependence on the deposition technique. The nanohardness measurements must be performed carefully since the indents should not be too large. Fortunately the DLC films have an extremely flat surface with a roughness $R_{a}$ of $0.05 \mathrm{~nm}$ which allows measurements with an accurate surface reference level. 


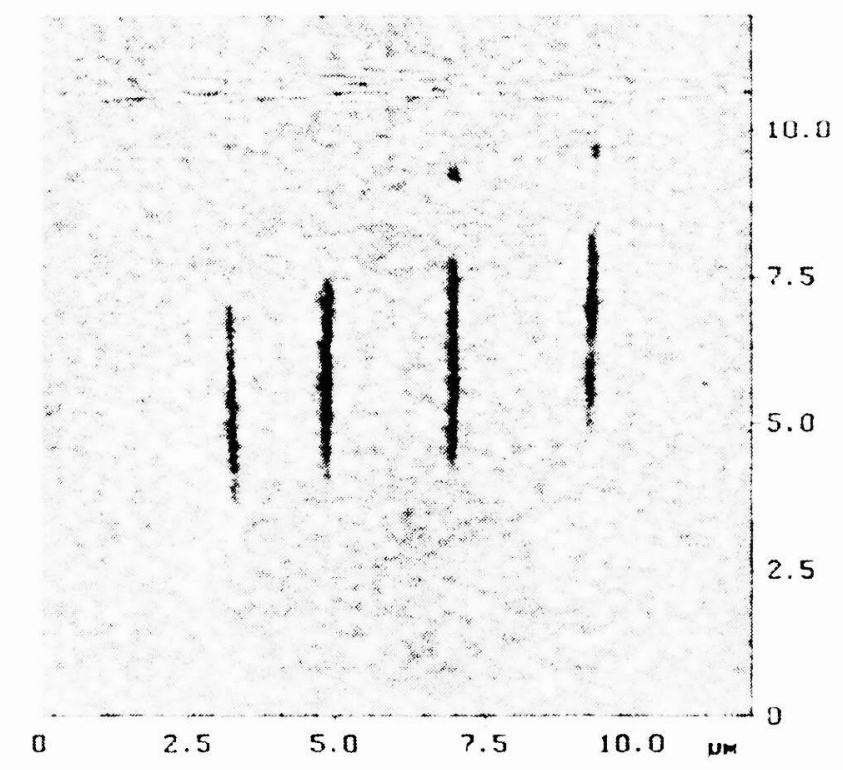

a
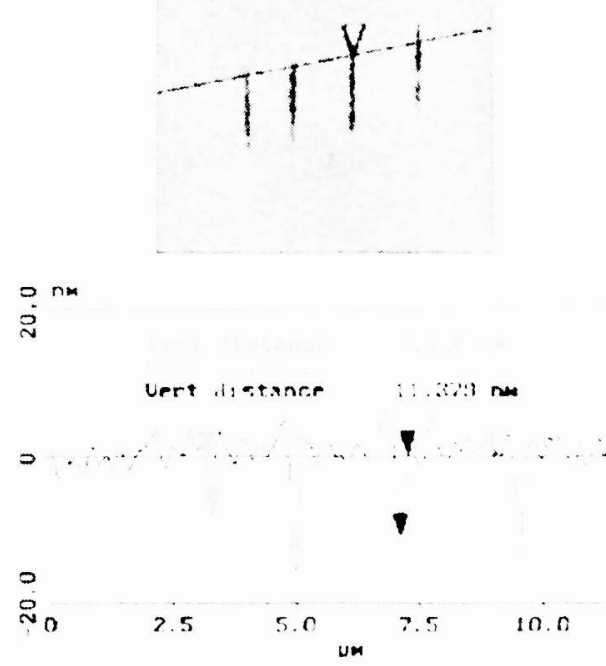

b

Fig. 4. SFM image of scratches in C60 on mica (a) with cross section analysis (b).

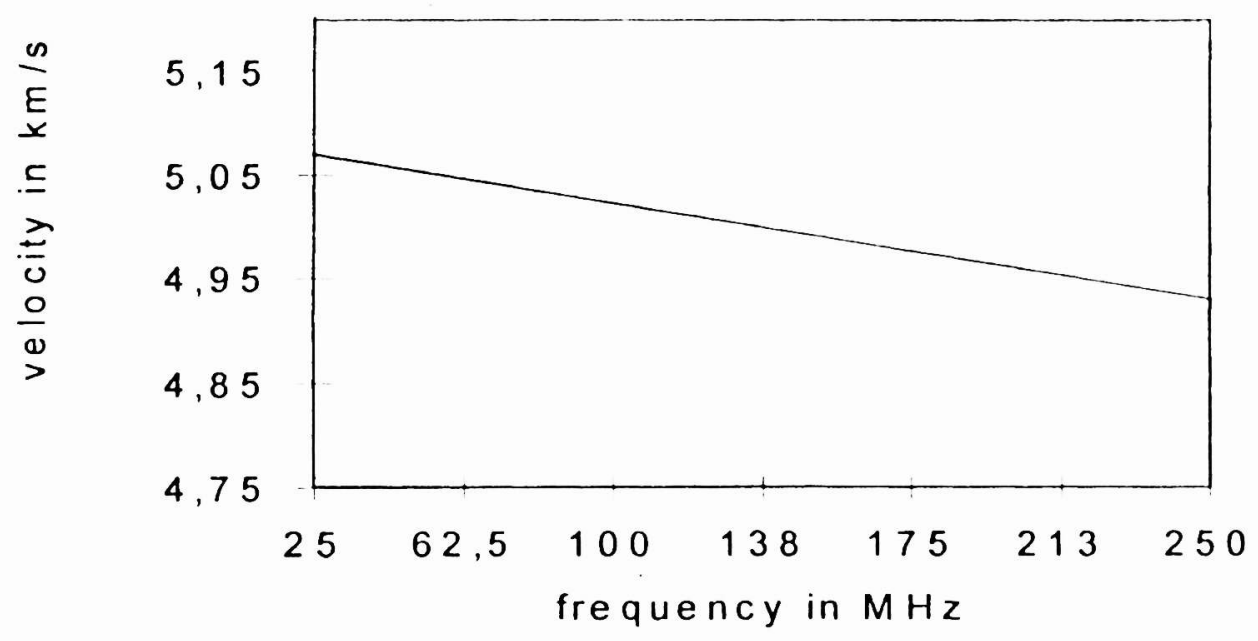

Fig. 5. Frequency dependence of the phase velocity for propagation in C60 film on silicon.

In Fig. 6 the relation between hardness and Young's modulus for various carbon films is shown. It is obvious that a linear dependence with a factor of 0.058 between nanohardness and Young's modulus exists. With increasing Young's modulus also the nanohardness increases. The nanohardness values of the DLC films are larger than the hardness of silicon and lie between 7 and $30 \mathrm{GPa}$. For hard coatings a Young's modulus between 300 and $350 \mathrm{GPa}$ is found compared to Young's modulus of diamond of 1040 GPa. The density of the DLC films was determined by a float method. For these studies the DLC films are removed from the substrate and the films material was suspended in a liquid with a density gradient. Electron energy loss spectroscopy can be also used to estimate the film density. Films prepared at increased deposition temperatures do not remove easily and exactly from the substrate because of their good adherence. The density variation of different carbon film samples deposited with various techniques is given in Fig. 7. The density of the carbon films varies between 1.9 and $3.3 \mathrm{~g} / \mathrm{cm}^{3}$. This is a sensitive parameter for the Young' modulus determination. Data from the literature have been included ${ }^{4,6}$. 


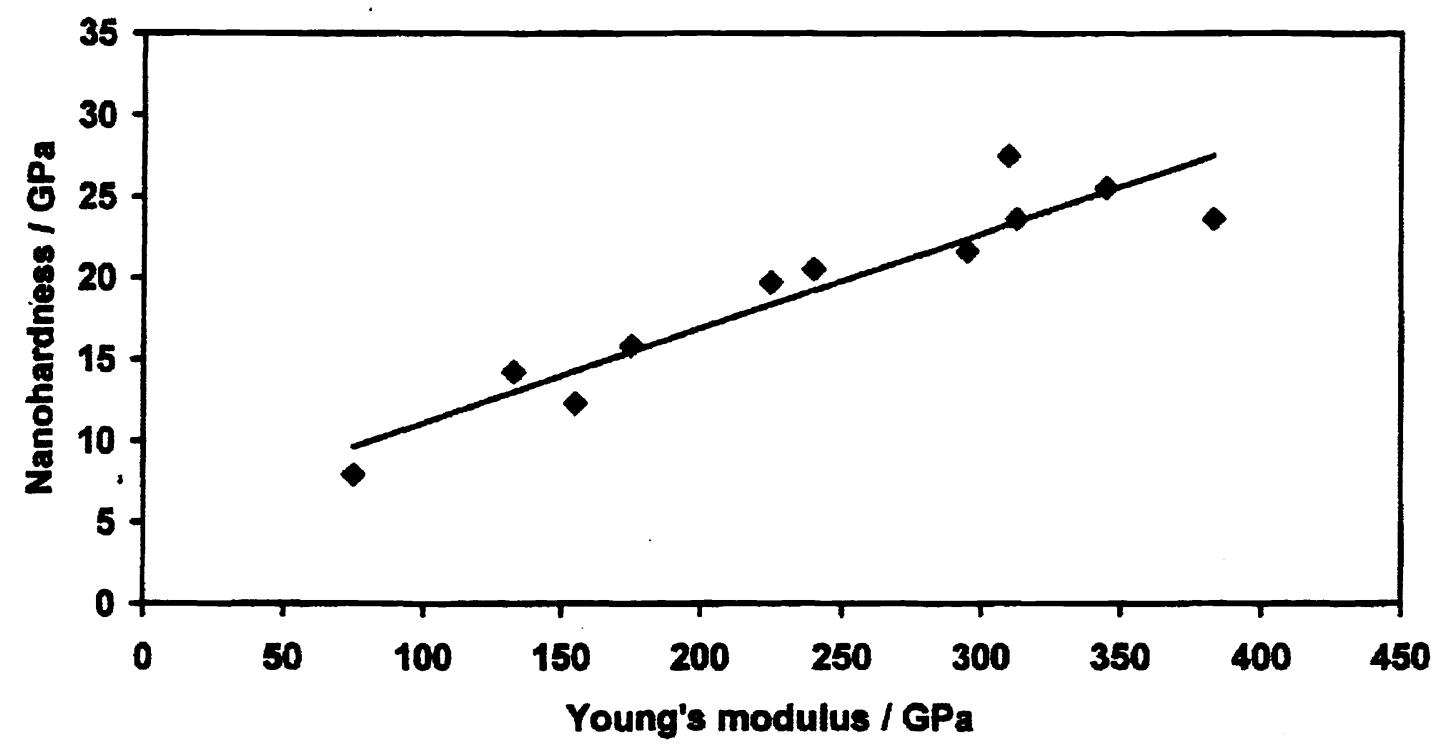

Fig. 6. Correlation between Hardness and Young's modulus for various carbon films.

Young's modulus

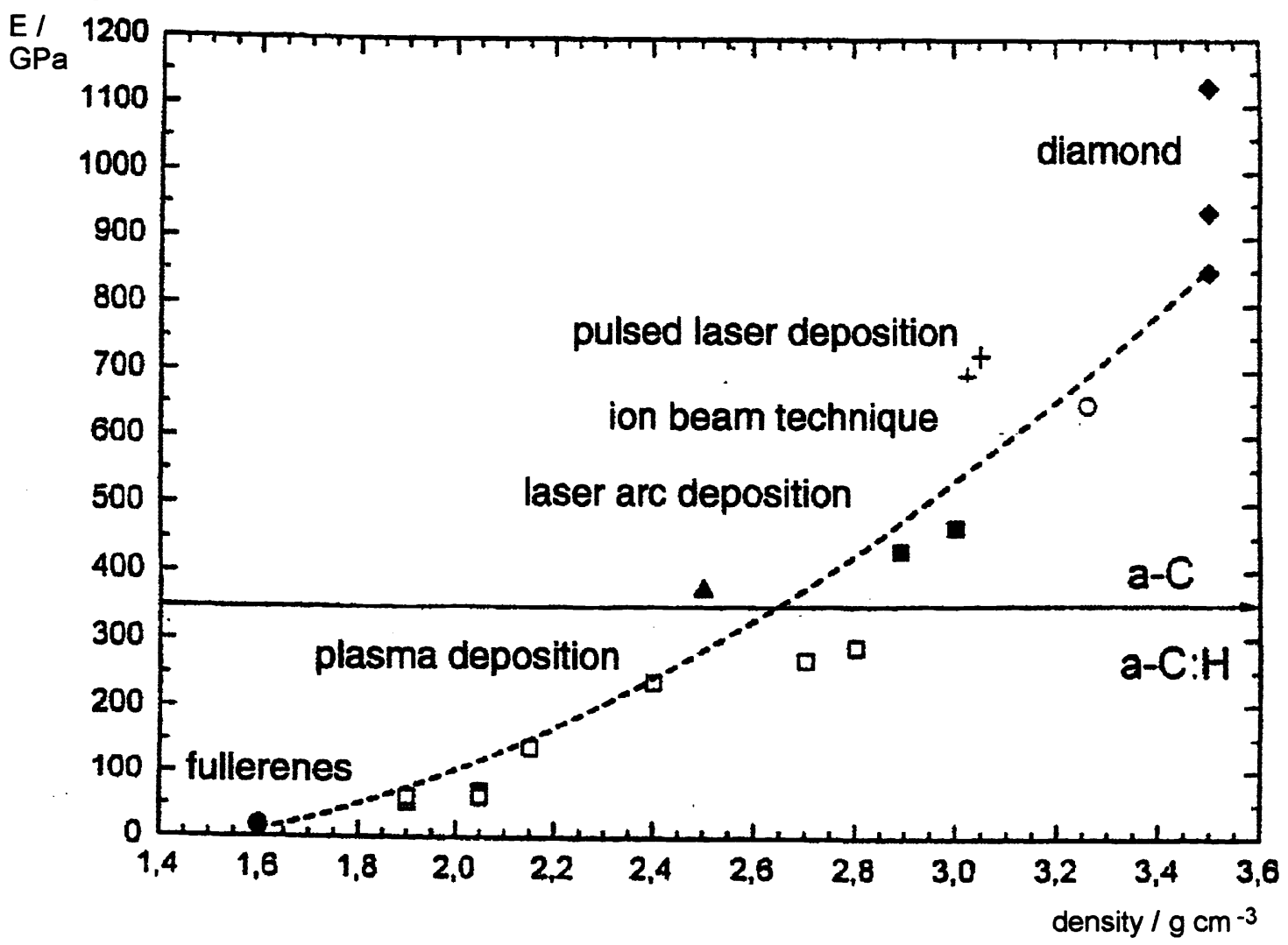

Fig. 7. Young's modulus versus density of various carbon films deposited with different techniques. 


\section{CONCLUSION}

Nanohardness and sound wave propagation measurements as new analysis techniques have been successfully applied to investigate mechanical properties of thin $\mathrm{C}_{60}$ and other carbon films. The very small indents are preferentially suitable to characterise thin films and very hard materials. A linear relation between nanohardness and Young's modulus could be found. Further work is necessary to improve the model of interaction between tip and material during the dynamical measurements of the load-displacement curve on nanoscale level. Computer simulations studies would be helpful for a better understanding of the process and are in progress.

\section{REFERENCES}

1. A. Richter, R. Ries, K. Szulzewsky, B. Pietzak and R. Smith, "The growth mechanisms and morphology of $\mathrm{C}_{60}$ films on different substrates", Surface Science 394, pp. 201-220, 1997.

2. Diamond and Diamond-Like Film Applications, ed. P.J. Gielisse, Technomic Publishing Company, Inc., Lancaster 1997.

Properties and Characterization of Amorphous Carbon Films, eds. I.I. Pouch and S.A. Alterovitz, Trans Tech Publications, Aedermannsdorf, Switzerland 1990.

3. W.C. Oliver and G.M. Pharr, "An improved technique for determining hardness and elastic modulus using load and displacement sensing indentation experiments", J. Mater. Res. 7, pp. 1562-1583, 1992.

4. D. Schneider, H.-J. Scheibe, Th. Schwarz and P. Hess, "Characterization of thin diamond-like carbon films by ultrasonic surface waves", Diamond and Related Mat. 2, pp. 1396-1401, 1993.

5. H. Coufal, K. Meyer, R.K. Grygier, M. de Vries, D. Jenrich and P. Hess, " Measurement of the elastic properties of evaporated C 60 films by surface acoustic waves”, Appl. Phys. A 59, pp. 83-86, 1994.

6. H.-J. Scheibe and B. Schultrich, "DLC film deposition by laser-arc and study of properties", Thin Solid Films 246, pp. 92-102, 1994. 